\title{
De la acumulación a la apropiación: una reflexión acerca del espacio público en la ciudad contemporánea
}

\author{
Da acumulação à apropriação: uma reflexão sobre o espaço público na \\ cidade contemporânea
}

From accumulation to appropriation: a reflection on the public space in the contemporary city

Fran Morente

Universitat de Vic, Vic, Catalunya, Spain

\section{Resumen}

El giro espacial en las ciencias humanas marca un punto de no retorno en el modo de conceptualizar la relación del ser humano con el espacio. Con la ciudad de fondo, tiempo, espacio y personas se imbrican en una transformación continua. Siguiendo esta estela, el presente artículo hace una aportación teórica al conectar territorio, ciudad y espacio público para ahondar en el conocimiento de éste último. Para ello recorremos tres escalas distintas: partimos de la instrumentalización global del territorio en pos de la acumulación, la fragmentación de la ciudad y la disolución de la identidad urbana y, finalmente, las presiones sobre el espacio público. La organización instrumental del territorio en centros y periferias transforma las ciudades en complejos palimpsestos sociales, y su espacio público, el lugar de encuentro democrático entre anónimos, en lugares donde la individualidad peligra. ¿Existe una réplica desde la microescala? A través de pensadores espaciales como Harvey, Augé y Lefebvre, se presenta, pues, una discusión teórica sobre la tensión entre sistema y sujeto, cosificación y liberación, estructuración y experiencia, en el escenario de la ciudad contemporánea.

Palabras clave: Geografía urbana. Territorio. Ciudad. Espacio público. Derecho a la ciudad.

\section{Resumo}

A virada espacial em ciências humanas marca um ponto de não retorno na forma de conceituar a relação entre seres humanos e espaço. Com a cidade ao fundo, tempo, espaço e pessoas estão interligados e em transformação contínua. Seguindo essa trilha, este artigo intenta uma contribuição teórica conectando território, cidade e espaço público, a fim de aprofundar o conhecimento sobre esse último. Para fazer isso, passamos por três escalas diferentes: começamos a partir da instrumentalização global do território em busca da acumulação, falamos da fragmentação da cidade e da dissolução da identidade urbana e, finalmente, das pressões sobre o espaço público. A organização instrumental do território em centro e periferias transforma as cidades em palimpsestos sociais complexos e seu espaço público, ponto de encontro democrático entre pessoas anônimas, em locais nos quais a individualidade está em perigo. Existe uma réplica a partir da microescala? Através de pensadores desse espaço, como Harvey, Augé e Lefebvre, apresenta-se uma discussão teórica sobre a tensão entre sistema e sujeito, reificação e libertação, estruturação e experiência no cenário da cidade contemporânea.

Palavras-chave: Geografia urbana. Território. Cidade. Espaço público. Direito à cidade.

FM es doctor en Derecho, Economía y Empresa (UVIC), investigador, e-mail: fjmp.1984@gmail.com 


\begin{abstract}
The spatial turn in human sciences marks a point of no-return in the conceptualization of the relationship between the human being and space. With the city as a battlefield, time, space and people are imbedded in a continuous transformation. Following this trail, this article makes a theoretical contribution to connecting territory, city and public space; deepening the knowledge of the latter. To do this we go through three different scales: starting from the global instrumentalization of the territory in pursuit of accumulation; the fragmentation of the city and the dissolution of the urban identity; and finally, the pressures on the public space. The instrumental organization of the territory in centers and peripheries transforms cities into complex social palimpsests, and to their public space, the democratic meeting place between anonymous people, in places where individuality is in danger. Is there a replica from the microscale? We present, through spatial thinkers such as Harvey, Augé and Lefebvre, a theoretical discussion on the tension between system and subject, reification and liberation, structuring and experience, in the scene of the contemporary city.
\end{abstract}

Keywords: Urban geography. Territory. City. Public space. Right to the city.

\section{Introducción}

El espacio público posee un papel central en la geografía contemporánea; su rol en la ciudad, sea como configurador de la dimensión urbana (Wittmer, 2017) o, más psicoanalíticamente, como síntoma (Carmona \& Matos Wunderlich, 2012), está fuera de toda duda. En él se inscriben y manifiestan los flujos macroeconómicos y los cuerpos íntimos (Serres, 1996; Sennett, 2004), en una suerte de frágil democracia espacial (Parkinson, 2012), donde lo público y lo privado, lo económico innominado y lo social y personal se mezclan en una tensión difícil de resolver (Paquot, 2015), siendo el reflejo de su pluralidad consustancial (Gehl, 2011). Precisamente esta complejidad y riqueza del espacio público ha suscitado un notable interés en los scholars; el espacio público es controversial (Iveson, 1998) y aglutina las contradicciones propias de vivir conjuntamente en la ciudad (Soja, 1989).

Esto ha contribuido sobremanera a una pluralidad de interrogaciones en relación a este, desde muy diversas perspectivas teóricas y prácticas (Estévez Villarino, 2012). El espacio urbano, en tanto que bisagra de lo urbano, es un punto de partida excelente para examinar y entender la ciudad en toda su amplitud, tanto práctica como ontológicamente (Gehl, 2011). Una búsqueda en Questia (2017) del término public space arroja nada menos que 201.774 resultados, muestra del excelente estado de salud del topic y de la ciertamente caótica amalgama de estudios que lo abordan. Siendo el espacio público un concepto heterogéneo (Smith \& Low, 2006), no podemos esperar un reflejo ordenado en su traslación a su producción científica. En relación con la producción científica reciente de los últimos quince años, las temáticas cubren un amplio espectro. Las investigaciones especializadas más recurrentes, y casi diríamos clásicas, recurren al caso de estudio de uno o varios espacios públicos, en concreto para estudiar dinámicas espaciales aprehensibles por el investigador social. En este primer subconjunto de estudios, el uso y exclusión de ciertos colectivos sigue siendo un tema predilecto (Bonilla \& Gómez, 2015; Azpeitia et al., 2017), pues permite acotar la investigación del espacio público a unas pocas variables constatables en campo a través de prácticas etnográficas. Muy en relación con este subgrupo, están los estudios que relacionan la privatización del espacio público (Coll Ramis \& Seguí Llinàs, 2016) con lo que ha venido a llamarse 'el declive del reino público' [the decline of public realm] (Banerjee, 2001). En otro subgrupo de estudios más teóricos, conscientes de la necesidad de renovación de las herramientas conceptuales, encontramos aquellos que buscan con ahínco nuevas epistemologías para apresar la heterogeneidad del espacio público, como puede ser a través de la Actor Network Theory (Estévez Villarino, 2012), o desarrollando filosóficamente el concepto para ampliar y recentrar sus atributos epistémicos básicos (Salcedo \& Caicedo, 2008). 
Muy vinculado a este, y desde una perspectiva sociológica, un tercer subgrupo de estudios pone de relieve la dimensión social del espacio público, ya sea desde el muy habermasiano prisma de discursos entrecruzados (Paquot, 2015), esto es, como confluencia de producción social, o ya sea desde su capacidad de generar capital social, es decir, como productor de socialización (Ijla, 2012). En un cuarto subgrupo, hallamos una vertiente más política, donde las personas se unen en un colectivo de acción política: el espacio público como manifestación de la expresión y el sentir ciudadano (Rouet, 2014) y como fiel reflejo de la imagen e imaginería colectiva (Wittmer, 2017). Si consideramos el espacio público como discurso, pero también, y en especial, como práctica espacial, podemos definir dos subgrupos más. En el quinto subgrupo, mucho más cercano a las prácticas espaciales in situ, se ahonda en la apropiación lefebvriana espacial de los espacios públicos cotidianos por parte de los ciudadanos (García García et al., 2016; Margier, 2017), en la cual nos extenderemos más adelante; la apropiación haría más habitable la ciudad. En el sexto, y último subgrupo, se presta atención al diseño del espacio público, tanto ligado a la calidad del espacio público para incrementar la calidad urbana general (Barliana et al., 2014) como a la reconstrucción de un nuevo espacio público con vistas a una regeneración urbana profunda de grandes segmentos de las ciudades (García-Doménech \& Martí-Ciriquián, 2013; Carmona, 2015).

Sin tratar de ser exhaustivos, quisiéramos dar cuenta con estos seis subgrupos de estudios de la variedad de enfoques que encontramos en una creciente bibliografía. En todos ellos aparece la fricción entre la dominación de la cotidianeidad social y la creatividad ciudadana (Iveson, 1998). Por todo ello, la principal y humilde aportación de este paper está en conectar teóricamente la fuerza de acumulación que domina, como un espectro, la ordenación del territorio, con la apropiación espacial del espacio público por las personas en su quehacer cotidiano. Inserto, entonces, en lo que Lacoste (2014) denomina la espacialidad diferencial, recorreremos tres escalas distintas territorio, ciudad y espacio público-, para conectar lo macro con lo micro, en un ejercicio de profundizar en la capacidad de resistencia y de réplica del espacio público. Como señala Garfinkel (1991), en las ciencias sociales, lo que damos por hecho [taken for granted], lo más evidente y al mismo tiempo lo más oculto, debe abrirse y verbalizarse, pues allí radican las luchas y las oposiciones entre las estructuras y los sujetos. Ese es nuestro propósito e interés.

\section{Territorio}

\section{Acumulación y organización del territorio}

No es un secreto: el carácter inherentemente expansionista y dinámico del capitalismo viene en buena medida determinado por su naturaleza acumulativa. Necesarias para su perduración, en las crisis endémicas del sistema capitalista, Harvey $(1977,1992)$ ve la aspiración, por un lado, de expandir la capacidad productiva y, por el otro, de renovar las condiciones y aumentar los límites del proceso de acumulación. De este modo se consolida un 'nuevo nivel' de acumulación del capital que expande los límites del mercado, es decir, la capacidad de recepción de mayores niveles de producción por medio de la penetración capitalista en nuevas actividades, la creación de necesidades sociales a ser saciadas por nuevos productos, la estimulación del crecimiento demográfico y la extensión hacia nuevos territorios no colonizados. En la medida en que contribuyen a la circulación del capital, el transporte y la ubicación devienen elementos de plusvalía. Harvey (1992) es claro: el territorio deviene escenario de guerras y mercancía.

De este análisis se desprende, por una parte, que la producción se concentra en unos pocos puntos privilegiados que organizan el territorio mediante la coerción del binomio centros-periferias (Harvey, 1977; Parkinson, 2012), dando lugar a distribuciones territoriales y sociales desiguales (Mendizàbal, 2004); y por la otra, que la velocidad adquiere un papel preponderante (Virilio, 1997a, p. 11):

[...] el poder es siempre el poder de controlar un territorio mediante mensajeros, medios de transporte y de transmisión. Independientemente de la economía de la riqueza, un estudio de lo político no puede hacerse sin un estudio de la economía de la velocidad.

De ahí la claridad de la consigna: el espacio debe ser abolido a favor del tiempo (Harvey, 1977; Virilio, 1997a; Jessop et al., 2008; Sassen, 2003). Se postula, pues, la racionalización geográfica del territorio con fines utilitaristas, en pos de la optimización 
ulterior, que atenúe las resistencias hacia el proceso de acumulación (Harvey, 1977). La concentración masiva de recursos en ciertos puntos (Sassen, 2003; Gehl, 2011) y el intercambio inmediato sin obstrucción de fronteras (Jessop, 2002) conducen al aniquilamiento de la distancia o a un mundo entendido como espacio confinado y de confinamiento (Virilio, 1997a) o mundo pequeño (Knox, 2002), que reduce al territorio 'sobrante' a una inmensa extensión yerma desprovista de acontecimientos (Baudrillard, 1983). El ámbito de acción capitalista no se limita tan sólo al plano económico y territorial, sino también al social y cultural (Mendizàbal, 2004). La hegemonía de un sistema económico basado en la continua generación de bienes -producción-y su ávida e inmediata recepción - el consumo - debe ir acompañada de productores y consumidores en la misma frecuencia de onda mental, compartir - pese a la falsa diversificación que supuso el salto al postfordismo - unos patrones conductuales y valores -que no gustos ni preferencias- análogos, esto es, una homogeneización cultural asentada sobre discursos performativos (Touraine, 1973; Lipovetsky, 1987; Jameson, 1991; Zukin, 1995; Debord, 1995; Lyotard, 1997; Mattelart, 2006; Bordieu, 2008).

Stricto sensu, la globalización denomina el proyecto de construcción de un espacio homogéneo de valorización, de unificación de las normas de competitividad y de rentabilidad a escala planetaria. Debería limitarse a significar el proyecto de capitalismo mundial integrado. Pero la terminología transgrede las fronteras de la geoeconomía y las geofinanzas para irradiarse hacia la sociedad. [...] El léxico de la economía global se transforma en vector de la uniformización de las formas de deciry de leer el destino del mundo (Mattelart, 2006, p. 96-97).

La conectividad de los puntos 'interesantes' del planeta y la generación de interdependencias, la comprensión espacio-temporal, el ensamblaje integración/desintegración, la fragmentación social y la complejidad creciente redundan en la generación de un caos orquestado (Bateson, 1977) para unos fines determinados y beneficiosos para una minoría privilegiada (Amendola, 2000; Parker, 2004; Jessop et al., 2008), en cuyo núcleo la industria y la producción de bienes quedan desposeídos de su importancia en favor de la transacción y los intercambios simbólicos (Zukin, 1995), de la pura especulación en un mundo no de hechos sino de virtualidades (Baudrillard, 2000); un mundo donde la promesa nunca colmada, es decir, el deseo, domina la economía (Amendola, 2000).

\section{Red de ciudades mundiales}

Dentro de este panorama territorial se insiere la importancia de la ciudad y el fenómeno urbano (Sassen, 2003; Knox, 2002). La predicción de Weber, en la cual para el 2030 más del $60 \%$ de la población sería urbana, ha dejado de ser descabellada para convertirse en toda una realidad (Parker, 2004). Esta acumulación requiere de núcleos que orquesten el utilitarismo territorial (Harvey, 1992; Lefebvre, 1991). La urbanización debe considerarse un fenómeno no sólo geográficamente muy remarcable, donde las ciudades, más que nunca, ejercen de ejes globales de la organización espacial y evolución social, tanto de fenómenos lejanos - globales - como cercanos locales - (Knox, 2002). Soja toma prestado de Jacobs el concepto de sinecismo, a través del cual se puede hablar de condiciones interdependientes y creativas derivadas de compartir un mismo lugar, que alentaría la producción y los flujos de creatividad fructíferos para la totalidad de la sociedad (Benach \& Albet, 2010).

Auspiciada por el auge de las telecomunicaciones, la globalización económica ha tejido una abstrusa maraña urbana de jerarquías, móviles y desterritorializadas, de intensas y complejas estructuras de poder, por donde circula con extrema rapidez una economía cada vez más desmaterializada y digitalizada (Sassen, 2003). Castells sostiene que, en la situación actual, el espacio de lugares ha cedido ante el espacio de flujos (Castells, 2003; Parkinson, 2012), siendo urgente una nueva forma de entender el rol de las ciudades (Friedmann, 1986). Génova, Venecia y Amberes, epítomes de la expansión imperial clásica, han cedido hace mucho tiempo el protagonismo a Nueva York, Londres y Tokio como executive managers del espacio global (Knox, 2002; Sassen, 2003). Estas, entre otras, ejercen a diferentes escalas de intersecciones, y han pasado a denominarse, según la teoría geográfica anglosajona ${ }^{1}$,

\footnotetext{
${ }^{1}$ Más allá Weber, para quien comercio e intercambio determinan el carácter urbano (Parker, 2004), las tres referencias fundamentales son: (a) Geddes; (b) Hall (1966) en su estudio de siete World Cities (Londres, París, el Ranstad, el área Rin-Ruhr, Moscú, Nueva York, Tokio); y (c) Friedman (1986) que organiza el mundo en núcleo, periferia y semiperiferia.
} 
ciudades mundiales [World Cities] $]^{2}$. En tanto que nódulos dominantes, estratégicos y ultracomunicados, las ciudades mundiales actúan como (a) organizadoras y centros de control de flujos de material, capital, información y transporte; (b) ubicación preferencial de las sedes corporativas; (c) interfície entre lo global y lo local, por lo cual están unidas a una constelación de pequeñas ciudades; (d) combinación y producto de la altamente polarizada división del trabajo a escala internacional y de la construcción de las redes globales (Friedmann, 1986; Knox, 2002; Sassen, 2003). Por consiguiente, las ciudades mundiales no son las más ricas ni las más grandes ni las más pobladas, sino las que poseen el mayor grado de conectividad y flexibilidad, aquellas capaces de articular y generar los diversos flujos globales y de atraer y multiplicar el capital extranjero (Amendola, 2000; Sassen, 2003).

El resultado ha sido la descentralización económica y la consolidación de la ideología de la competitividad. La férrea competencia y la diferencia de capacidades entre ciudades han tejido una red de diferencias entre un mundo rápido -producción flexible, patrones de consumo sofisticado, organización global - y otro lento - ruralidad, declive manufacturero, desconexión cultural y de tipos estándar de vida - (Knox, 2002), siendo este último quien queda relegado al parecer a poco más que una zona de futuro expolio, marginal y estigmatizada (Gehl, 2011).

\section{Ciudad}

\section{Disolución, fragmentación, privatización}

Lewis Mumford se refiere a las ciudades como locus y focus de la civilización, lugares de experimentación, auténticos espejos de la modernidad (Mumford, 1968). Si bien ha perdurado la visión entusiasta de la ciudad, entendida en tanto espacio de obertura y oportunidades, de aventura y riesgo, no es menos cierto que esa misma esencia peligra (Parker, 2004). Según Ascher (2004) asistimos al triple proceso negativo de la ciudad, a saber, disolución, fragmentación y privatización, que queda perfectamente reflejado

\footnotetext{
${ }^{2}$ Un punto de referencia ineludible es el departamento de geografía de Loughborough University, desde el cual se gestiona la red de investigación GaWC (2017). Otra referencia mucho más popular, políticamente correcta, catchy y trendy es la famosa 'clase creativa' de Richard Florida (2005).
}

(Vicent Rufí, 2003) en la incesante multiplicación terminológica que trata de definir la emergencia de un nuevo concepto de ciudad. Ascher (2004) cifra en tres las revoluciones urbanas, según el tipo de sociedad (ver Tabla 1).

Uno de los intentos más destacados es la metápolis de Ascher que, según la interpretación de Vicent Rufí (2003), es una ciudad hipercontemporánea e intercomunicada sin centro ni unidad de espacios reales y virtuales, una inspiración futurista de crecimiento radio-céntrico, lineal o en metástasis, que fragmenta la lógica christalleriana en espacios diferenciales y discontinuos de muy heterogéneas centralidades multipolarizadas. La desposesión territorial a la que aboca la acumulación capitalista tiene por fruto estas ciudades fragmentadas (Ascher, 2004), especulativas (Amendola, 2000), hiperconectadas (Harvey, 1992), donde las identidades se ven forzadas a mercantilizarse (Parker, 2004). La emergencia del reino privado y el enorme aumento de la movilidad geográfica desemboca en una emergente transformación de la ciudad y en una reconstrucción de las identidades y experiencias urbanas (Carmona \& Matos Wunderlich, 2012). Amendola (2000) cita a Ihab Hassan para describir la experiencia postmoderna en la ciudad: (a) ambigüedad y discontinuidad; (b) fragmentación (ruptura de meta-relatos, patchwork, collage, pastiche); (c) desligitimización masiva; (d) identidades ligeras y triviales; (e) hedonismo; (f) ironía, hibridación, y parodia; (g) carnavalización; (h) reino de la suspicacia y escepticidad; (j) causalidad y estocasticidad.

\section{Espacio comodificado}

Georg Simmel retrataba al cosmopolita como a un ser nervioso e intelectual incapaz de adecuarse a la intensidad urbana, hastiado, acompañado pero solitario, reservado para con sus congéneres (Capel, 1975). Para algunos autores, el perfil promovido por el capitalismo se sintetiza en la transnational bourgeoise, hedonistas irredentos, fascinados y frívolos, americanizados y/o sensibles a la alteridad superflua y homogeneizada en la diferenciación de la oferta (Amendola, 2000; Carmona \& Matos Wunderlich, 2012) en su libidinal desenfreno de la práctica social como fantasía de partes recicladas (Amendola, 2000; Paquot, 2015). Más visibles que lo visible, pura exhibición, transparencia de la plenitud vacía, gente 
Tabla 1 - Dinámica de la modernización occidental en las tres revoluciones urbanas modernas

\begin{tabular}{|c|c|c|c|}
\hline & Comunidad & Sociedad Industrial & Sociedad Hipertextual \\
\hline Vínculos sociales & $\begin{array}{l}\text { Poco numerosos, cortos, } \\
\text { sin diversificar, poco } \\
\text { mediatizados, estables, } \\
\text { fuertes y multinacionales }\end{array}$ & $\begin{array}{l}\text { Más numerosos, de varios tipos, evolutivos, } \\
\text { fuertes, en vías de especialización }\end{array}$ & $\begin{array}{l}\text { Muy numerosos, muy variados, mediatizados } \\
\text { y directos, frágles, especializados }\end{array}$ \\
\hline Tipo de solidaridad & Mecánica & Orgánica & Conmutativa \\
\hline $\begin{array}{l}\text { Territorios sociales } \\
\text { (espacio de las relaciones) }\end{array}$ & $\begin{array}{l}\text { Autárquicos y cerrados en } \\
\text { gran medida, con centralidad } \\
\text { local }\end{array}$ & $\begin{array}{l}\text { Integrados en un conjunto más grande, } \\
\text { entreabiertos, con base nacional }\end{array}$ & $\begin{array}{l}\text { Abiertos, múltiples, cambiantes, con escalas } \\
\text { variables (de local a global) reales y virtuales }\end{array}$ \\
\hline Morfología socio-territorial & Alveolar & Areolar & Reticular \\
\hline Paradigmas dominantes & $\begin{array}{l}\text { Creencias, tradición y } \\
\text { continuidad, destino, fuerza, } \\
\text { autoridad, sabiduría }\end{array}$ & $\begin{array}{l}\text { Razón universal Funcionalidad, simplificación } \\
\text { y especialización } \\
\text { Democracia participativa }\end{array}$ & $\begin{array}{l}\text { Compleiidad, } \\
\text { incertidumbre, autorregulación, flexibilidad } \\
\text { Gobernanza }\end{array}$ \\
\hline Actuaciones & Repetitivas y rutinarias & Racionales & Reflexivas \\
\hline Regulaciones principales & Costumbres, jefe & Estado y leyes & $\begin{array}{l}\text { Sistemas estatales, subsidiarios, derecho y } \\
\text { contratos, sociedad, opinión pública }\end{array}$ \\
\hline $\begin{array}{l}\text { Actividades económicas } \\
\text { dominantes }\end{array}$ & Agrícolas & Industriales & Cognitivas \\
\hline Cultura & Predominantemente local & Con componentes socio-profesionales & $\begin{array}{l}\text { Diversificada e hibrida (multipertenencia social } \\
\text { y cultural) }\end{array}$ \\
\hline Tipo urbano dominante & Ciudad-mercado & $\begin{array}{l}\text { Armadura urbana, eerarquizada y ciudades } \\
\text { industriales }\end{array}$ & Sistema metropolitano \\
\hline Instituciones & $\begin{array}{l}\text { Parroquias, cantones y } \\
\text { jurisdicciones, Estado-nación }\end{array}$ & $\begin{array}{l}\text { Comunas, jurisdicciones, administración } \\
\text { centralizada, Estado-nación del bienestar } \\
\text { Pactos, alianzas y tratados }\end{array}$ & $\begin{array}{l}\text { Aglomeraciones, países, regiones, Estado- } \\
\text { nación del bienestar } \\
\text { Organizaciones internacionales y } \\
\text { supranacionales, ONG }\end{array}$ \\
\hline
\end{tabular}

Fuente: Ascher (2004).

obscena que no representan nada (Baudrillard, 2000). La cita -la técnica predilecta de la postmodernidad-y el tiempo instantáneo - ni cronológico ni histórico que han traído las TICs, han confinado la experiencia urbana al presente perpetuo (Jameson, 1991; Virilio, 1997b; Amendola, 2000), limitándola a un proceso desposeído de fin, a un simulacro proyectado al infinito (Amendola, 2000; Parker, 2004), al reino del kitsch y el palimpsesto (Carmona \& Matos Wunderlich, 2012).

En la ciudad contemporánea el mindscape (el panorama del alma y de la cultura urbana) se ve enfrentado al cityscape (el panorama físico de la ciudad); el urban planning al urban design (valorar, excluir, enfatizar); el movimiento moderno (funcionalidad, racionalidad, homegeneidad) al postmodernismo (diferencia, identidad y placer); la moralidad y la educación a la jarana y la lucha contra el tedio (Amendola, 2000); o en palabras de Baudrillard: las fachadas relucientes sin ningún rostro en su interior (Parker, 2004).

En nuestra ciudad efímera que a un tiempo se desmiembra y se reconstruye (Parker, 2004; Rouet, 2014), en la ciudad esquizofrénica, volátil, polarizada (Sennett, 1991), de estratificación opaca, contingente (Harvey, 1992), desprovista de significado y vacía de contenido (Baudrillard, 2000), irónica, espectacular y donde nada es definitivo (Sorkin, 2004), y todo es susceptible de ser transferido, el tiempo y el espacio se han capitalizado, las experiencias cotidianas se han trivializado (Amendola, 2000), y los derechos se han pisoteado (Harvey, 1992; Paquot, 2015). La virada del valor de uso -experiencia- al valor de cambio transacción- queda reflejada en el segundo circuito del capital, donde es posible relacionar dialécticamente la acumulación con la desposesión [accumulation by dispossession] (Harvey, 2008). La urbanización, 
apunta Lefebvre (1972a, 1972b, 1973, 1976, 1978, 1991) y enfatiza Zukin (1993) y Harvey (2008), es imprescindible para la supervivencia del capitalismo; consiste en su instrumento principal de orquestar (Wittmer, 2017). Paquot (2015) reclama el título de urbanización planetaria [urbanisation planétaire] para denominar a este urbanismo que uniformiza, desde la pluralidad de usos restringidos a la transacción, el goce y la pérdida democrática.

Y esto resulta todavía más patente en las ciudades globales, que estructuran su espacio interior a costa de desterritorializar, una desterritorialización basada en la desconexión con el territorio, la muerte del espacio polidimensional y la pérdida de la identidad y la historia, y donde los sujetos se ven arrastrados por los flujos globales y locales, y los lugares se reconstruyen, pero no se refuerzan (Knox, 2002). Una ciudad que, a fuerza de ofrecer una panoplia de diversiones, acaba desposeyéndola de pluralidad democrática (Margier, 2017). El producto estrella de la reestructuración es el espacio mercancía [commodified space], el terreno o territorio que se alquila, se vende o del que pueden obtenerse beneficios relativos a la titularidad de su propiedad, privilegiando el valor de cambio (Parker, 2004) y una materialización determinada a un uso concreto de las posibilidades urbanas (Gaffikin et al., 2010).

\section{Espacio público}

\section{Giro espacial}

Los modelos de los prismas espacio-temporales de Hägerstraand (1970), los mapas mentales de Lynch (1970, 1984), los visionarios escritos de Lefebvre (1976, 1978, 1991) y el empeño de Soja (1989, $1996,2008)$ y Thrift $(2000,2006)$, por citar algunos ejemplos, han dado rendida cuenta de la importancia del espacio en nuestras vidas.

El giro espacial [spatial turn] ha afectado a las ciencias sociales y humanas a lo largo de los últimos veinte años, haciendo temblar sus cimientos con nuevas voces, territorios y significados, y ha remarcado la relevancia del pensamiento material, de la práctica, de la poiésis en la creación del mundo (Thrift, 2006). La revolución griega de la geometría trajo consigo el yugo del espacio matematizado y euclidiano que durante siglos silenció el resto de espacios (Serres, 1991). El espacio, no obstante, ha ido deshaciéndose de los adjetivos que se le atribuían: inocuo, aséptico, isotrópico e inmóvil, ficción geométrica pasiva e inerte (Soja, 1989, 1996).

Fue Lefebvre quien, en 1974 en La Production de l'Espace, restableció lo físico, mental e imaginado del espacio (Soja, 1996; Shields, 1999), construcción en progreso permanente de las (inter)relaciones espaciales en su coexistencia y simultaneidad. En esta seminal obra, Lefebvre presenta la tríada espacial: el espacio concebido [espace conçu] o representación espacial, el espacio percibido [espace perçu] o práctica espacial y el espacio vivido [espace vecu] o espacio de representación y resistencia (Soja, 1996; Lefebvre, 1991; Shields, 1999). El espacio concebido es el de los técnicos y arquitectos, y, por lo tanto, se refiere a las magnitudes empíricamente mesurables de un mundo material único, objetivo, cuantitativo, euclidiano y cartografiable, que reproduce fielmente el discurso hegemónico y perpetúa las relaciones de producción. Con todas las contradicciones esenciales de la vida cotidiana, el espacio percibido, por su parte, es subjetivo e imaginado, aprehensible no sin dificultades por medio de representaciones cognitivas y simbólicas, y, por ende, ideológicamente manipulable. Finalmente, experimentado en los momentos plenos de presencia se encuentra el espacio vivido, cuya irrupción contradictoria -liberadora u opresiva- posibilita la entrada de la complejidad y las contradicciones de la vida (Lefebvre, 1991; Soja, 1996; Shields, 1999).

El espacio vivido, el tercer espacio [thirdspace] es, para su epígono Soja (1996), un nuevo modo de ver, interpretar y actuar, que tiene por objetivo cambiar y participar en el devenir del mundo; obertura radical, en tanto que lugar de intercambio, punto de partida de nuevas exploraciones de la existencia (Soja, 1996; Benach \& Albet, 2010). De modo que la producción del espacio no sería un producto cualquiera, sino un instrumento, político e ideológico, reproducción de las relaciones de producción, que se construye a partir de la práctica de la vida cotidiana (Lefebvre, 1976, 1991; Soja, 1989, 1996, 2008).

\section{Espacio público}

Todo tiempo, todo modo de producción y toda sociedad producen su propio espacio (Lefebvre, 1976) y es precisamente ahora, con la destrucción y reconstrucción de las formas urbanas de largo alcance 
(Soja, 2008), en la sobreexposición (Virilio, 1997b), la obscenidad (Baudrillard, 2000) y la reproducción de los no-lugares (Augé, 1993, 2004), en la incapacidad de representar nuestras experiencias (Jameson, 1991), cuando se requiere un centro subjetivo y colectivo, un lugar e instrumento de inscripción en el mundo (Lefebvre, 1973, 1991; Amendola, 2000; Knox, 2002). La clase dominante industrial y el Estado (en su aceptación poulantziana) encajonan y desnaturalizan la vida por medio de la administración 'racional' y la explotación sistemática del espacio, utilizando un doble poder: (a) la propiedad privada del suelo y (b) la estrategia de representación espacial. Los espacios cosificados, neutros e instrumentales, planificados desde la racionalidad de los mercados, segregan lo urbano y lo despojan de vida cotidiana, de simultaneidad y complejidad (Lefebvre, 1976, 1991). El espacio público que conocemos y experimentamos está anestesiado (Soja, 1996), y juega en contra de las tres grandes cualidades de toda ciudad: urbanidad, diversidad y alteridad (Paquot, 2015).

El espacio público es la ciudad, el espacio principal del urbanismo y la ciudadanía (Gehl, 2011), un lugar de resistencia (Lefebvre, 1976, 1991) postmoderna (Soja, 1996) y creadora de significados (Certeau, 2000), que edifica redes sociales espontáneas u organizadas (Rouet, 2014). El espacio público es un derecho cívico (Marcuse, 2014) y un modo de representar las vidas (Goffman, 1963; Ijla, 2012; Wittmer, 2017). En la arquitectura de la decepción y el urbanismo monofuncionalista que se articula por yuxtaposición a-geográfica e intercambiable de ornatos, cortoplacista y tendencioso, obsesionado por la vigilancia, la segregación, la exclusión y la simulación (Borja \& Muxí, 2003; Sorkin, 2004), el espacio público es una herida mortal en el ideal de reproducción de espacios para sirvientes (Sorkin, 2004), pues representa los encuentros múltiples (Ijla, 2012) de la esfera social donde se da el debate público (Marcuse, 2014). A las nuevas manifestaciones del urbanismo como producto de masas (arquitectos superstars, trophy buildings, place marketing, etc.) (Amendola, 2000), el pugnaz Mike Davis les reprocha que, a causa de ellas, "[...] la ciudad ha sido dividida y fragmentada por opulencia. El resultado. [...] la destrucción de cualquier espacio urbano verdaderamente democrático" (Davis, 2004, p.178). La presión neoliberalista ejercida sobre el espacio público expulsa lo público de este, distinguiendo entre los usos supuestamente 'correctos' de los supuestamente 'incorrectos' o 'malos' (Iveson, 1998); la exclusión y la segregación espacio-social corresponden a las herramientas de este tipo de gestión (Wittmer, 2017). Lo público adquiere, en el espacio público, dos significados y dos modelos:

Put simply, topographical models of public space use 'public' to denote spaces of sociability in the city where one's actions are visible to others, while procedural models of public space use 'public' to donate spaces where one may take part in collective discussions about common interests and issues (Iveson, 2007, p. 17).

Así, la zonificación y la privatización son la caricatura del movimiento moderno (Gehl, 2011) y la normativización social el modo de regular la creatividad desviada de la ciudadanía (Davis, 1990; Margier, 2017). El propio Sennett (2004) realiza una distinción crítica entre bordes [borders], los cuales son porosos y proclives al intercambio, de los límites [boundaries], que encierran y estancan las dinámicas; un espacio que nos apresa o bien un espacio que nos incita a crear en la alteridad. En consecuencia, el espacio público ideal debería rehuir lo residual - entre calles y edificios -, lo vacío - ubicado por razones políticas - y lo especializado -con un uso estrictamente definido (Wittmer, 2017), es decir, debería dar continuidad a la ciudad y vertebrar el tejido urbano, ser multifuncional y polisémico, accesible, inclusivo e integrador de la mezcla social, llevando a cabo la función iniciática de socialización (Borja \& Muxí, 2003).

\section{Inscripción cotidiana y centralidades recuperadas}

Si la ciudad es la maximización de las posibilidades -oportunidad de contacto, apuesta por la diferenciación, mixtura funcional y social- es preciso multiplicar sus espacios de encuentro y elección para que no sean propiedad de nadie (Gehl, 2011); sólo de este modo podrán crearse nuevos debates, cruces de destinos, simbolismos y significados (Augé, 2004). Democratizar, arguye Sennett (1991) también significa dignificar y dar cabida a lo sucio, peligroso y denso, a la dislocación y a la desorientación, al reverso dionisiaco de la ciudad que, en contraposición al ideal apolíneo del arquitecto, sea una fuente más de riqueza cultural y creatividad; hacer, en definitiva, de la calle y la plaza focos desde donde construir 
la ciudad. Sin embargo, aprehender lo que ocurre en el espacio público, no plantea sino dificultades: la superficie moldea y codifica el sentido; el tiempo se reduce al instante; fortuitos, fluctuantes y simultáneos, los acontecimientos -la mirada, el gesto- concitan el acontecimiento; los rituales prescritos, los modales, pesan más que las apariencias; todos, desconocidos, extraños y extranjeros (Margier, 2017). En el espacio público, cuya esencia es la alteridad, la consistencia es tanto más natural, cuanto más frágil y precaria; no sólo existe la necesidad manifiesta de pluralidad y divergencia, sino también la de enmarañamiento y anquilosamiento (Goffman, 1963; Duque, 2011; Estévez Villarino, 2012). La fluidez masiva, las digresiones incidentales -confluencia/dispersión-, la profusión de lo inesperado y la precariedad de los vínculos o la ausencia de reciprocidad, caracterizan la turbulenta interacción en este escenario circunstancial. Joseph (1988) recuerda que para Hannerz, en un espacio público, donde se da cabida al ritual de socialización, las relaciones más importantes son las que todavía no se han dado, porque sólo así existe en su capacidad innata de trastornar la relación entre identidad colectiva y un territorio, pues no existe territorio sin proclamación. Será preciso, por tanto, aceptar la desorganización parcial y transitoria para explorar nuevas fronteras -siempre negociadas- del espacio público (Joseph, 1988) en el que la vida cotidiana se despliega y reconfigura las centralidades (Lefebvre, 1976, 1983). La centralidad para Lefebvre (1976) son redes, circuitos de comunicación, de información y de intercambios; se trata de una parte esencial y constitutiva de lo urbano y consustancial al derecho a la ciudad.

[...] No se puede llegar a forjar una realidad urbana [...] sin la existencia de un centro: sin un agrupamiento de todo cuanto puede nacer en el espacio y producirse en él, sin encuentro actual o posible de todos los objetos o sujetos (Lefebvre, 1976, p. 19).

La lucha cotidiana por recuperar la centralidad es fundamental en las ciudades, y el espacio público es el campo de batalla (Lefebvre, 1976).

¿Cómo definir la vida cotidiana? Nos rodea y nos cerca; en el mismo tiempo y el mismo espacio, está en nosotros y nosotros en ella y estamos fuera de ella, tratando sin cesar de proscribirla para lanzarnos en la ficción y lo imaginario, nunca seguros de salirnos de ella, aun en el delirio del sueño (Lefebvre, 1978, p. 85).

En la práctica de la vida cotidiana las necesidades devienen deseos, y los momentos de presencia, inscripciones en el mundo. En lugar del empobrecedor espacio simple, el espacio lefebvriano es considerado en tanto que realización e inclusión en la simultaneidad del mundo en una serie de tiempos ritmados de la ciudad (Lefebvre, 1978, 1991). Para ello Lefebvre distingue entre el 'hábitat' - descripción morfológica asignable, aislable y localizable - de 'habitar' - la acción - , y ofrece el prometeico concepto de apropiación: acto revolucionario, acción creadora de los ciudadanos sobre la ciudad y el mundo, contribución a la obra [oeuvre], inscripción en el tiempo de una vivencia. Apropiarse es sublimar la existencia, regresar a la vida cotidiana plena y devolver a lo urbano lo que nunca debió de perder, el deseo y el desequilibro, lo lúdico y lo imprevisible (Lefebvre, 1973); tan pronto apropiamos, esculpimos nuestro mundo (Lefebvre, 1978). Con la apropiación de los espacios públicos empezamos con la 'extensión de nuestro hogar' [extensión du chez-soi] y acabamos, colectivamente, con la 'constitución de un hogar' [constitution d'un chez-soi] (Margier, 2017).

\section{Conclusiones}

El recorrido hasta aquí ha sido una apuesta por conectar las tensiones de lo macro sobre lo micro, y de circunscribir la potencia de la apropiación para revertir, en parte, la fuerza de la acumulación capitalista. Grandes estructuras, flujos económicos y amplios arcos temporales se enfrentan en el espacio público a sujetos desagregados, a micromovilizaciones y a la cotidianeidad del día a día. Lo cotidiano, lo minúsculo, transmuta el orden natural de las cosas; la ciudad deviene ouevre por medio de la práctica cotidiana de los ciudadanos (Lefebvre, 1973). Según Certeau (2000), por medio de las distintas apropiaciones o maneras de hacer, los ciudadanos transgreden las estructuras de poder impuestas, alterando su funcionamiento ${ }^{3}$. El espacio (público), en tanto que práctica social y

\footnotetext{
${ }^{3}$ La acción en tanto que pensamiento que no piensa de Certeau (2000) sintetiza la muy en boga Teoría No Representacional [Non-Representational Theory]. Sendos ejemplos son (a) Thrift (2000) en Afterwords; y (b) la Teoría del Actor-Red [Actor-Network Theory] de Latour (2008).
} 
acto de creación, metaforiza la ciudad, haciéndola propia (Certeau, 2000, p. 46):

Habitar, circular, hablar, leer, caminar o cocinar, todas estas actividades parecen corresponder a las características de astucias y sorpresas tácticas: buenas pasadas del "débil" en el orden construido por el "fuerte", arte de hacer jugadas en el campo del otro, astucia de cazadores, capacidades maniobreras y polimorfismo, hallazgos jubilosos, poéticos y guerreros.

La producción capitalista, es decir, racional, optimizada, agresiva, global, falsamente descentralizada y, por encima de todo, espectacular, que se caracteriza por la producción de una heteróclita masa de productos, tiene una poderosa contrarréplica silente, dispersa y oculta, que no se caracteriza por la producción de productos sino por sus modos de empleo; en la recepción y apropiación se metaforiza el orden dominante y se desvían las propuestas iniciales hacia nuevas rutas (Certeau, 2000). En este contexto, la identidad debe ser entendida en los términos que propone Sassen (2003) o Thrift (2000), a saber, como work in progress, imbricación, o más bien mixtura no estática donde lo local -o interno- es puesto en relación con lo global -0 externo ${ }^{4}$.

Si bien la tendencia negativa global a la privatización [commodification] de los espacios públicos dificulta la creación de una identidad y ejerce de disruptor del sentimiento de pertenencia (Sorkin, 2004; Harvey, 2008), el derecho a la ciudad, derecho no ya solo al acceso a los recursos urbanos, sino a las centralidades, a la libertad de crear y recrear las ciudades, nuestros espacios y a nosotros mismos, no debe dejar de reclamarse (Harvey, 2008). Derecho primordial a la vida urbana, transformada y renovadora, que colme los deseos, materialice las fantasías, preñe la realidad de significados y se despliegue ante nuestros ojos; la finalidad manifiesta es el descubrimiento del arte de vivir la ciudad como obra de arte, en suma, en palabras de Lefebvre (1973), es la realización de lo imposible-posible.

Es esta la vía a seguir por los investigadores sociales de la ciudad contemporánea.

\footnotetext{
${ }^{4}$ Inspirador de la Teoría No Representacional, Serres (1995, p. 123) escribió en los años sesenta: “[...] Y las redes de comunicación ahora reclutan, para su conexión pública, a la humanidad casi entera, que se convierte así en el sujeto de la obra al mismo tiempo que en su objeto".
}

\section{Referencias}

Amendola, G. (2000). La ciudad postmoderna. Madrid: Celeste Ediciones.

Ascher, F. (2004). Los nuevos principios del urbanismo: el fin de las ciudades no está a la orden del día. Madrid: Alianza Editorial.

Augé, M. (1993). Los “no lugares", espacios del anonimato: una antropología de la sobremodernidad. Barcelona: Gedisa Editorial.

Augé, M. (2004). ¿Por qué vivimos? Barcelona: Gedisa Editorial.

Azpeitia, C. A., Martínez, S. A., \& Nájera, R. M. S. (2017). Habitabilidad urbana en el espacio público, el caso del centro histórico de Toluca, Estado de México. Sociedad y Ambiente, 5(13), 129-169.

Banerjee, T. (2001). The future of public space: beyond invented streets and reinvented places. APA Journal, 67(1), 9-24.

Barliana, M. S., Cahyani, D. P., \& Paramita, B. (2014). The urban quality, public space, and social capital: departing from comparison of three cities. International Journal of Humanities and Social Science, 4(1), 180-190.

Bateson, G. (1977). Steps to an ecology of mind. New York: Ballantine Books.

Baudrillard, J. (1983). The ectasy of communication. In H. Foster (Ed.), The antiaesthetic: essays on postmodern culture (pp. 126-134). Los Angeles: Bay Press.

Baudrillard, J. (2000). Las estrategias fatales. Barcelona: Editorial Anagrama.

Benach, N., \& Albet, A. (2010). Edward W. Soja: la perspectiva postmoderna de un geógrafo radical. Barcelona: Arcadia Editorial.

Bonilla, M. H., \& Gómez, S. G. (2015). Conflicto espacial, exclusión y espacio público en la centralidad urbana de Xalapa, Veracruz. Urbe. Revista Brasileira de Gestão Urbana, 7(3), 281-294. http://dx.doi.org/10.1590/21753369.007.003.A004.

Bordieu, P. (2008). Capital cultural, escuela y espacio social. Buenos Aires: Siglo XXI.

Borja, J., \& Muxí, Z. (Eds.). (2003). El espacio público: ciudad y ciudadanos. Barcelona: Diputació de Barcelona, Xarxa de Municipis y Editorial Electa. 
Capel, H. (1975). La definición de urbano. Estudios Geográficos, (138-139), 265-301.

Carmona, M. (2015). Re-theorising contemporary public space: a new narrative and a new normative. Journal of Urbanism, 8(4), 373-405. http://dx.doi.org/10.1080/17 549175.2014.909518.

Carmona, M., \& Matos Wunderlich, F. (2012). Capital cities: the multiple complex public space of a global city. London: Routledge.

Castells, M. (2003). L'era de la informació: economia, societat i cultura. Barcelona: UOC.

Certeau, M. (2000). La invención de lo cotidiano: artes de hacer. México: Universidad Iberoamericana, Biblioteca Francisco Xavier Clavigero.

Coll Ramis, M. A., \& Seguí Llinàs, M. (2016). La privatización de los espacios públicos destinados al ocio y al turismo mediante la regulación del estacionamiento de vehículos: análisis de casos en la isla de Mallorca. Documents d'Analisi Geografica, 62(2), 255-273. http://dx.doi.org/10.5565/ rev/dag.272.

Davis, M. (1990). City of quartz: excavating the future in Los Angeles. New York: Verso.

Davis, M. (2004). Fuerte Los Ángeles: la militarización del espacio urbano. In M. Sorkin (Ed.), Variaciones sobre un parque temático: la nueva ciudad americana y el fin del espacio público. Barcelona: Gustavo Gili.

Debord, G. (1995). La sociedad del espectáculo. Santiago de Chile: Ediciones Naufragio.

Duque, F. (2011). Arte urbano y espacio público. Res Publica, 26, 75-93.

Estévez Villarino, B. (2012). La idea de espacio público en geografía humana. Hacia una conceptualización (crítica) contemporánea. Documents d'Analisi Geografica, 58(1), 137-163. http://dx.doi.org/10.5565/rev/dag.200.

Florida, R. (2005). Cities and the creative class. New York: Routledge.

Friedmann, J. (1986). The world city hypothesis. Development and Change, 17(1), 69-83. http://dx.doi. org/10.1111/j.1467-7660.1986.tb00231.x.

Gaffikin, F., McEldowney, M., \& Sterrett, K. (2010). Creating shared public space in the contested city: the role of urban design. Journal of Urban Design, 15(4), 493-513. http:// dx.doi.org/10.1080/13574809.2010.502338.
García García, A., Fernández Salinas, V., Caravaca Barroso, I., \& González Romero, G. (2016). Actividades creativas, transformaciones urbanas y paisajes emergentes: el caso del caso norte de Sevilla. Documents d'Analisi Geografica, 62(1), 27-54. http://dx.doi.org/10.5565/rev/dag.245.

García-Doménech, S., \& Martí-Ciriquián, P. (2013). ¿Renace el espacio público? Angulo Recto, 5(2), 21-36.

Garfinkel, H. (1991). Studies in ethnomethodology. Cambridge: Polity.

Gehl, J. (2011). Life between buildings: using public space. Washington: Island Press.

Globalization and World Cities - GaWC. (2017). Loughborough: Loughborough University. Recuperado el 25 de junio de 2017, de http://www.lboro.ac.uk/gawc

Goffman, E. (1963). Behaviour in public places: notes on the social organization of gatherings. New York: The Free Press. Hägerstraand, T. (1970). What about the people in regional science? Papers in Regional Science, 24(1), 7-24. http:// dx.doi.org/10.1111/j.1435-5597.1970.tb01464.x.

Hall, P. (1966). The world cities. London: Weidenfeld and Nicolson

Harvey, D. (1977). La geografía de la acumulación capitalista: una reconstrucción de la teoría marxista. Documents d'Analisi Geografica, 1, 109-142.

Harvey, D. (1992). The condition of postmodernity: an enquiry into the origins of cultural change. Cambridge: Blackwell.

Harvey, D. (2008). The right to the city. New Left Review, $53,23-40$

Ijla, A. M. (2012). Does public space créate social capital? International Journal of Sociology and Anthropology, 4(2), 48-53. http://dx.doi.org/10.5897/IJSA11.084.

Iveson, K. (1998). Putting the public back into public space. Urban Policy and Research, 16(1), 21-33. http:// dx.doi.org/10.1080/08111149808727745.

Iveson, K. (2007). Public and the city. Oxford: Blackwell. http://dx.doi.org/10.1002/9780470761748.

Jameson, F. (1991). Ensayos sobre el posmodernismo. Buenos Aires: Ediciones Imago Mundis.

Jessop, B. (2002). The future of the capitalist state. Cambridge: Polity Press. 
Jessop, B., Brenner, N., \& Jones, M. (2008). Theorizing sociospatial relations. Environment and Planning. D, Society \&Space, 26(3), 389-401. http://dx.doi.org/10.1068/d9107.

Joseph, I. (1988). El transeúnte y el espacio público urbano: ensayo sobre la dispersión del espacio público. Buenos Aires: Gedisa.

Knox, P. L. (2002). World cities and the organization of global space. In R. J. Johnston, P. J. Taylor \& M. J. Watts (Eds.), Geographies of global change (pp. 328-340). Oxford: Blackwell.

Lacoste, Y. (2014). La géographie, ça sert, d'abord, à faire la guerre. París: La Découverte.

Latour, B. (2008). Reensamblar lo social: una introducción a la teoría del actor-red. Buenos Aires: Ediciones Manantial.

Lefebvre, H. (1972a). La revolución urbana. Madrid: Alianza Editorial.

Lefebvre, H. (1972b). La vida cotidiana en el mundo moderno. Madrid: Alianza Editorial.

Lefebvre, H. (1973). El derecho a la ciudad. Barcelona: Península.

Lefebvre, H. (1976). Espacio y política: el derecho a la ciudad II. Barcelona: Península.

Lefebvre, H. (1978). De lo rural a lo urbano. Barcelona: Península.

Lefebvre, H. (1983). La presencia y la ausencia; contribución a la teoría de las representaciones. México: Fondo de Cultura Econónomica.

Lefebvre, H. (1991). The production of space. Oxford: Blackwell.

Lipovetsky, G. (1987). La era del vacío: ensayos sobre el individualismo contemporáneo. Barcelona: Editorial Anagrama.

Lynch, K. (1970). La imagen de la ciudad. Buenos Aires: Infinito.

Lynch, K. (1984). Good city form. Cambridge: Massachusetts Institute of Technology.

Lyotard, J.-F. (1997). La condición postmoderna. Madrid: Ediciones Cátedra.

Marcuse, P. (2014). The paradoxes of public space. Journal of Architecture and Urbanism, 38(1), 102-106. http:// dx.doi.org/10.3846/20297955.2014.891559.
Margier, A. (2017). Cohabiter l'espace public: conflits d'appropiation et rapports de pouvoir à Montréal et Paris. Rennes: PUR.

Mattelart, A. (2006). Diversidad cultural y mundialización. Barcelona: Paidós.

Mendizàbal, E. (2004). La explicación de procesos en geografía: el ejemplo de la geohistoria del capitalismo. Documents d'Analisi Geografica, 44, 149-165.

Mumford, L. (1968). La ciudad en la historia: sus orígenes, transformaciones y perspectivas. Buenos Aires: Editorial Infinito.

Paquot, T. (2015). L'espace public. París: La Découverte.

Parker, S. (2004). Urban theory and the urban experience: encountering the city. London: Routledge. http://dx.doi. org/10.4324/9780203471784.

Parkinson, J. R. (2012). Democracy \& public space: the physical sites of democratic performance. Oxford: Oxford University Press. http://dx.doi.org/10.1093/acprof:oso bl/9780199214563.001.0001.

Questia. (2017). Recuperado el 7 de diciembre de 2017, de http://questia.com

Rouet, G. (2014). Mobilisations citoyennes dans l'espace public. París: L'Harmattan.

Salcedo, M. A., \& Caicedo, S. C. (2008). El espacio público como objeto de estudio en las ciencias sociales y humanas. Revista Científica Guillermo de Ockham, 6(1), 99-115.

Sassen, S. (2003). Contrageografías de la globalización: género y ciudadanía en los circuitos transfronterizos. Madrid: Traficantes de Sueños.

Sennett, R. (1991). La conciencia del ojo. Barcelona: Versal.

Sennett, R. (2004). The resurgent city: the city as an open system. In Proceedings of the Leverhume International Symposium 2004. London: School of Economics. Recuperado el 7 de diciembre de 2017, de http://www.lse.ac.uk/ collections/resurgentcity/papers/richardsennet.pdf

Serres, M. (1991). Hermes V: el paso del noroeste. Madrid: Debate.

Serres, M. (1995). Atlas. Madrid: Cátedra.

Serres, M. (1996). Hermes I: la comunicación. Barcelona: Anthropos. 
Shields, R. (1999). Lefebvre, love \& struggle: spatial dialectics. London: Routledge.

Smith, N., \& Low, S. (2006). Introduction: the imperative of public space. In S. Low \& N. Smith (Eds.), The politics of public space. New York: Routledge.

Soja, E. W. (1989). Postmodern geographies: the reassertion of space in critical social theory. London: Verso.

Soja, E. W. (1996). Thirdspace: journeys to Los Angeles and other real-and-imagined places. Malden: Blacwkell.

Soja, E.W. (2008). Postmetropolis: estudios críticos sobre las ciudades y las regiones. Madrid: Traficantes de Sueños.

Sorkin, M. (Ed.). (2004). Variaciones sobre un parque temático: la nueva ciudad americana y el fin del espacio público. Barcelona: Gustavo Gili.

Thrift, N. (2000). Afterwords. Environment and Planning. D, Society \& Space, 18(2), 213-255. http://dx.doi.org/10.1068/ d214t.

Thrift, N. (2006). Space. Theory, Culture \& Society, 23(2-3), 139-146. http://dx.doi.org/10.1177/0263276406063780.
Touraine, A. (1973). La sociedad post-industrial. Esplugues de Llobregat: Ariel.

Vicent Rufí, J. (2003). ¿Nuevas palabras, nuevas ciudades? Revija za Geografijo, 2, 79-103.

Virilio, P. (1997a). La cibernética, la política de lo peor: entrevista con Philippe Petit. Madrid: Cátedra.

Virilio, P. (1997b). The overxposed city. In N. Leach (Ed.), Rethinking architecture: a reader in cultural theory. London: Routledge.

Wittmer, E. (2017). Aménager les espace publics: mettre en place le processus. Paris: Territorial Éditions.

Zukin, S. (1993). Landscapes of power: from Detroit to Disney World. Berkeley: University of California Press.

Zukin, S. (1995). The cultures of cities. Oxford: Blackwell.

Recibido: Ago. 28, 2017

Aprobado: Dic. 15, 2017 